\title{
Violence on Accessing Water and Sanitation Facilities - A Study among Women in Slums/Resettlement Colonies of Chennai City
}

\author{
Mageswari $\mathbf{S}^{1 *}$ and Gowtham $\mathbf{S}^{2}$ \\ ${ }^{1}$ Department of Geography, Queen Mary's College (A), Chennai, India \\ ${ }^{2}$ Public Health Researcher, Chennai, India
}

*Corresponding author: mage.2621@gmail.com

Received: 22-04-2020

Revised: 17-07-2020

Accepted: 28-09-2020

\begin{abstract}
Lack of access to water and sanitation facilities is a concern in India and it affects women and girls disproportionately by impacting on their health and dignity. Women in slums without water supplies and toilets within their homes are potentially vulnerable to different forms of violence. This study identified the different forms of violence faced by women on accessing water and sanitation facilities, differences within categories of slums, reasons for the same and compared it with resettlement colonies. Among the location-based categories on accessing water facilities, verbal abuse was found high $(90.7 \%)$ among the women of industrial slums, while physical abuse (18\%) and sexual abuse (8.7\%) was reported high in residential slums. During accessing sanitation facilities, verbal abuse was reported high (50\%) among women in industrial slums and sexual abuse was reported high (12\%) among the women in coastal slums. While in resettlement colonies it is found that all forms of violence were found to be low comparatively. The study also found that the time of water and sanitation access and distances negotiated to fetch water and to access sanitation as an influencing factor of the violence.
\end{abstract}

Keywords: Violence, Women, Slum, Water and Sanitation, Resettlement colonies

Slums are characterized by inadequate housing and poor infrastructure (Sverdlik, 2011). The slum dwellers battle many challenges in their day to day life, of which lack of water and sanitation facilities was the most critical one (United Nations Human Settlements Programme, 2003). Women and girls in four out of five households bear the most burden on fetching water (Kayser et al. 2019). They were restricted from freedom of movement and equal opportunities because on the fear of sexual violence which they face on accessing public facilities. The endless fights for water at the standpipes and harassments against them in public sanitation facilities, are echoed throughout the city, which makes the women to face both physical and psychological damage (Corburn \& Hildebrand, 2015; Subbaraman et al. 2013, 2014).

Unavailability, accessing conditions and locations are the factors that lead to violence in meeting their basic needs of water and sanitation (Lande, 2015; Mageswari, 2017). Women are seen greatly responsible and the pressure to fulfil their and family's demands leaves

How to cite this article: Mageswari, S and Gowtham, S. (2020). Violence on Accessing Water and Sanitation Facilities - A Study among Women in Slums/ Resettlement Colonies of Chennai City. Int. J. Soc. Sci., 9(03): 151-158. Source of Support: ICSSR-CWDS; Conflict of Interest: None क क 
them with no option but to accept unsafe conditions and to go through the violence and abuse. The conflicts arise among the women when the demand and competition for accessing the poor available resources increases (Bapat \& Agarwal, 2003; Gross et al. 2018; Raj et al. 2019). Thus, the poor women living in slums do not see opportunities to get motivated as compared to the rest of the city population, in achieving the social goals of high living standard and better environmental health; and as such, they are poorly equipped to take advantage of urban opportunities. And so, they are more vulnerable to fall prey to social evils. And also the everyday experiences of violence and suffering of women vary according to the class, locality, age and physical abilities of women (Chaplin \& Kalita, 2017). With this context, the study addressed the different forms of violence faced by women in urban slums and resettlement colonies on accessing water and sanitation facilities in Chennai city and identified the differences within the categories of slums (based on their locations). Further resettlement colonies were included as one of the categories to determine the developmental differences.

\section{MATERIALS AND METHODS}

The study adopted a cross-sectional mixed method design and conducted among the women in locationbased categories (residential slums, industrial slums, coastal slums and resettlement colonies) of Chennai city during 2016. Resettlement colonies were included to determine the impact of developmental differences on violence against women in accessing water and sanitation facilities. The sample location-based categories covering all the three administrative divisions and households were selected using purposive sampling method. A total of nine slums and two resettlement colonies were included, and women above 18 years who resided in the selected areas for at least the past one year were recruited for the study. The study recruited 550 women (50 per slum/resettlement colony) and a face to face interview was done using an interviewer-administered questionnaire. A focus group discussion (FGD) from each sample area with eight women participants and discussions were carried out with the help of photos depicting the slum situations and cores of the research issues.
Descriptive analysis for quantitative data was done using SPSS 14 software and results were interpreted as frequencies and percentages. The statistical association between the factors relating access to water and sanitation facilities and different forms of violence against women was done using Pearson's chi-square/ Fishers test, and a p-value of $<0.05$ was considered to be statistically significant. Scalogram analysis was done to find out the location-based category with highly affected women. Thematic analysis was done to identify the themes for the collected qualitative data. The audio recorded FGDs were transcribed as verbatim and translated into English. The other information like field notes and observation notes were also used during the analysis. Initially, the themes were identified from the interview guide, and then following the iterative process of reading, final themes were developed. Data description and interpretation was done using triangulation method. Written informed consent was obtained from all the participants before the commencement of the study.

\section{RESULT}

Women act as a primary responsible person to meet the household needs of water in addition to other domestic works. Even though the water facility is somewhat good when compared to the past, the needs of the slum people are not equally met. The socio-demographic characteristics of the study participants are given in table 1. Majority of women do not have individual water connection and toilet facilities at home and they were dependent on the public facilities which were inadequate and difficult to access. Women's choice and access to water and sanitation facilities were influenced by the location, distance, and time of available facilities and it differed between the selected location-based categories (table 2). These inadequacies and poor access exposed women folks to verbal, physical and sexual violence.

In spite of an increase in public water facilities, women of the slums struggle daily to fill her canisters of water with mental and physical agony. In their day-to-day life, women wait for a long time, are in need to shout, fight and be arrogant to fill their 'allotted' canisters and experience verbal, physical and sexual violence against them. 
Table 1: Socio-demographic characteristics of study participants

\begin{tabular}{|c|c|c|c|c|c|}
\hline & Variables & $\begin{array}{l}\text { Residential slum } \\
(\mathrm{n}=150)\end{array}$ & $\begin{array}{l}\text { Industrial slum } \\
(n=150)\end{array}$ & $\begin{array}{l}\text { Coastal slum } \\
(n=150)\end{array}$ & $\begin{array}{l}\text { Resettlement colony } \\
(\mathrm{n}=100)\end{array}$ \\
\hline \multirow{4}{*}{ Age } & $18-24$ & 16 & 14.7 & 16 & 13 \\
\hline & $25-35$ & 32.7 & 34.7 & 33.3 & 39 \\
\hline & $36-45$ & 31.3 & 31.3 & 32 & 31 \\
\hline & $>45$ & 20 & 19.3 & 18.7 & 17 \\
\hline \multirow{3}{*}{ Marital status } & Married & 71.3 & 74.7 & 77.3 & 76 \\
\hline & Widow & 10 & 12.7 & 10 & 12 \\
\hline & Separated & 8.7 & 2 & 2.7 & - \\
\hline \multirow{2}{*}{ Type of Family } & Joint & 12.7 & 14.7 & 32 & 5 \\
\hline & Nuclear & 87.3 & 85.3 & 68 & 95 \\
\hline \multirow{2}{*}{ Total members of family } & Two & 6 & 7.3 & 5.3 & 2 \\
\hline & Above five & 9.3 & 8 & 28.7 & 2 \\
\hline \multirow{3}{*}{ Type of House } & Kutcha & 36 & 40 & 34 & - \\
\hline & Semi-pucca & 18 & 12 & 50 & - \\
\hline & Pucca & 46 & 48 & 16 & - \\
\hline \multirow{6}{*}{ Educational Level } & Illiterate & 34.7 & 40 & 40.7 & 37 \\
\hline & Primary & 32.7 & 28 & 28.7 & 30 \\
\hline & High & 18.7 & 18 & 18.7 & 18 \\
\hline & Higher & 8.7 & 9.3 & 9.3 & 6 \\
\hline & UG & 5.3 & 4.7 & 1.3 & 9 \\
\hline & PG & - & - & 1.3 & - \\
\hline
\end{tabular}

"We are getting water in the mornings and the public toilet is opened for use at 7 am only. So, we have to access it without missing. So, we are used to wait in queues to access the toilet and then we run to water sites with our canisters. As every woman has to complete her morning chores and move on for other chores, they start to quarrel with each other saying that 'I only came first' as a common refrain in the quarrels. Most of the time the quarrel turns into severe verbal abuse and also a physical assault of sorts"
Exposure to bad and vulgar language during accessing the facilities makes them mentally disturbed and sometimes, the harsh and vulgar verbal abuses have led to physical assaults as well. The women who are abusers are also the victims some other time, in fight for water. Women are not only experiencing the abuses among themselves but they are also sometimes abused by men, which is mostly in the form of verbal abuse and to a certain extent it also led to sexual abuse. 
Table 2: Accessibility of water and sanitation facilities in location-based categories

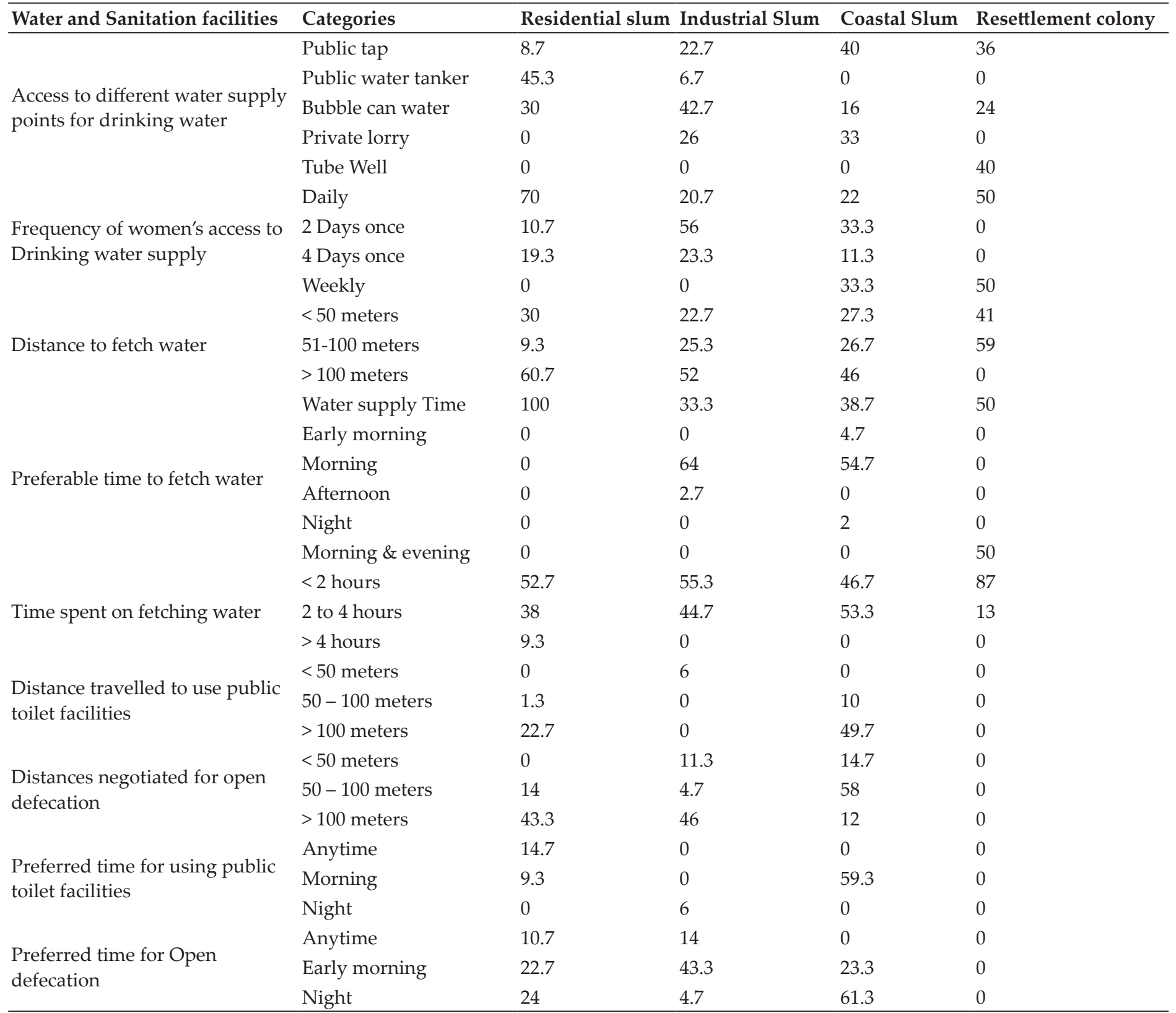

So many incidents have happened in this slum. Here is one: a lady of 38 years on returning home from work went to a public toilet in our area. There she was raped by her neighbours' teen. Due to the incident, that woman was traumatized and avoided all her neighbours. There was also a fight between both families, but as the teen's family had political backup, the woman's family did not report it to the police, fearing unpleasant consequences.
Most of the women faced sexual violence while accessing sanitation facilities. Men touch women's body on overcrowded situation, peep in sanitation facilities, expose themselves to women (flashing), involve in sexual assault and even rape have been reported by the study population. Almost all the participant has mentioned events related to sexual violence ("roll the woman on the ground", "tried to hold me", "pinch 
her backside", "hug the girl," etc.) and all had the fear of sexual violence in their living setting. The problem was much severe among adolescent age girls. One of the women who seem to be an all-time victim in water fights and sanitation practices has revealed her story of daily struggle (Box 1).

\section{Box 1: Verbal Abuse and Quarrels in the Slums}

I am 42 years old and the only female member of my family. I have been living in the slum for the past 38 years. For a long time, this area does not have any proper facilities, which make us fight for the available resources. Daily I have to fight and argue with some women of the area to fulfil the water needs of my family. Especially, a woman who is living near my house always fights with me. She always fetches more water than allotted. She never allows me and other women to fetch allotted numbers of canisters. When I or other women argue with her, she will start to use bad words and at one time even she pushed me down and stabbed me with her foot. I went to the police and complained about her. Police came, warned her, and told the community women to fetch only allotted canisters of water. However, even after that the woman fetched water as before. Now I am totally depressed and stressed, and so to avoid the situation I am walking very long distances to fetch water. I wake up late to avoid her and do my chores. For the past month, I have paid ₹ 400 to collect bore water from a house, which is a little far from my house. Apart from this tiring struggle, I also have to handle the sanitation needs. As our area doesn't have public toilets, I have to go before the sunrise or after the sunset to the rail tracks for defecation. As it is an open place, many times I was abused by the men- strangers. They mocked me using bad words and shouted at me using sexual words. And sometimes some men even described our bodies. In these situations, I felt ashamed and ran away back home. But I have no other choice and have to go there only bearing all the shame.
The frequency of women in location-based categories, who faced violence while accessing water and sanitation facilities in shown in Fig. 1 and 2 respectively. Among the location-based categories on accessing water facilities, verbal abuse was found high (90.7\%) among the women of industrial slums, while physical abuse $(18 \%)$ and sexual abuse $(8.7 \%)$ was reported high in residential slums. In resettlement colony, verbal abuse was found lowest (14\%) among the categories and no women reported physical and sexual abuse. During the access of sanitation facilities, verbal abuse was reported highly $(50 \%)$ among women in industrial slums and sexual abuse was reported high (12\%) among the women in coastal slums.

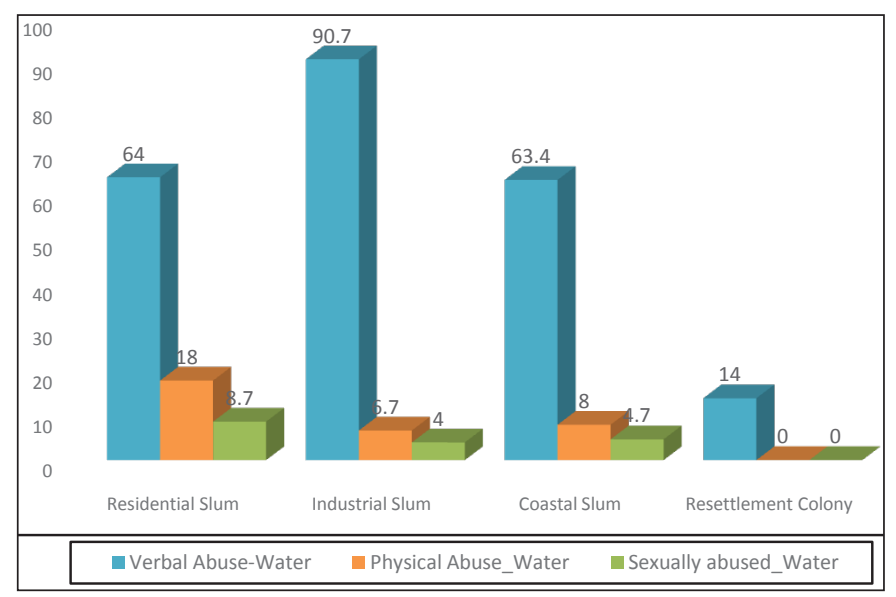

Fig. 1: Violence experienced by women in location-based categories in accessing water facilities

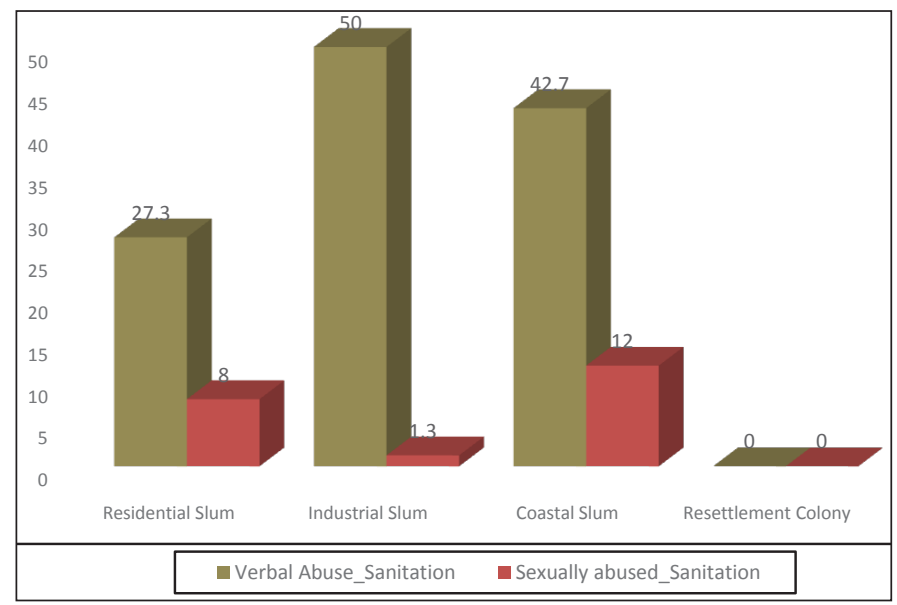

Fig. 2: Violence experienced by women in location-based categories in accessing sanitation facilities 
Association between Time and Distance of facilities and violence: The factors considered for the study are the time of water and sanitation access and distances negotiated to fetch water and to access sanitation, as these act as the base for the initiation of the problem/ violence. These factors are tested for relationships with verbal, physical and sexual abuse. The association between these factors is given in Table 3 .

The impact level of women in location-based categories: Using Scalogram analysis, the study found that the women of the coastal slums had highly experienced violence due to poor infrastructural facilities, while the industrial and residential slum women had a moderate impact and resettlement colonies women were less affected.

\section{DISCUSSION AND CONCLUSION}

The study explored the different forms of violence experienced by women in slums and resettlement colonies on accessing water and sanitation facilities in Chennai city. Overall 72.7 percent, 10.9 percent and 5.8 percent of women in slum experienced verbal, physical and sexual violence respectively which are attributable to inadequate water facilities. On accessing sanitation facilities, verbal and sexual abuse was experienced by 40 percent and 7.1 percent respectively. The study done in slums of Delhi reported 89.9 percentage of women experienced sexual violence on accessing sanitation facilities (Lennon, 2011), which is high when compared to our study findings. But the interview and discussion in the present study highlights that many women who undergo harassment are not ready to accept it due to many reasons like protecting their prestige in order to secure a good marriage, fear, shame, and maintenance of dignity, so the ground realities are often under-reported. Another study done in Mangolpuri and Kusumpur Pahari of Delhi reports different form of gender-based violence like teasing and whistling (32 percent), rape or assault (16 percent) and groping (12 percent) experienced by women due to lack of infrastructural facilities. This study also reported the greatest numbers of incidents of harassment and violence took place at open defecation sites (Chaplin \& Kalita, 2017) which are similar to our findings of high impact of violence on women of Coastal slums who are abused at open defecation sites along the beaches/open isolated spaces.

Many studies done in the slums of India (Bapat \& Agarwal, 2003; Chaplin \& Kalita, 2017; Hulland et al. 2015; Kulkarni et al. 2017; Lennon, 2011; Sahoo et al. 2015; Tiwari, 2015) reflect the findings of gender-based violence and water and sanitation accessibility. Similar findings on the prevalence of gender-based violence have been reported from many worldwide studies (Amnesty International, 2010a, 2010b; Kwiringira et al.

Table 3: Association between violence and time and distance factors

\begin{tabular}{|c|c|c|c|c|}
\hline Factors & Residential slum & Industrial slum & $\begin{array}{l}\text { Coastal } \\
\text { slum }\end{array}$ & $\begin{array}{l}\text { Resettlement } \\
\text { colony }\end{array}$ \\
\hline Verbal abuse and distance of water source & $<0.001$ & $<0.001$ & $<0.001$ & 0.146 \\
\hline Verbal abuse and time spend to fetch water & $<0.001$ & 0.022 & $<0.001$ & 0.205 \\
\hline Physical abuse and distance of water source & $<0.001$ & 0.462 & 0.668 & * \\
\hline Verbal abuse and distance to practice open defecation & $<0.001$ & 0.002 & $<0.001$ & * \\
\hline Verbal abuse and time to practice open defecation & $<0.001$ & 0.007 & $<0.001$ & * \\
\hline Sexual abuse and distance to access public lavatory & 0.001 & 1 & 0.036 & * \\
\hline Sexual abuse and distance to practice open defecation & 0.008 & 0.497 & 0.134 & $*$ \\
\hline
\end{tabular}


2014; Massey, n.d.; Sommer et al. 2015; Tutu \& Stoler, 2016). Though many studies have been done around the world relating water and sanitation and violence on women, only very few studies have looked into the slum geographies and facilities (Kulkarni et al. 2017) and no study has addressed the differences between slums. The present study highlights the differences between slums on violence against women and compared with resettlement colonies. Verbal and physical abuse was highly reported among women in Industrial and residential slums respectively, which was because of the high population density and less supply of water. The less frequency of water supply increases the demand for water which in turn increases the time spent in long queues, crowded gatherings and the competition to fill the canisters. This situation leads to verbal abuse and in extreme cases physical and sexual abuse. Further this situation hinders their social relationship with their neighbours and affects their mental health.

Women in the coastal slums reported high number of sexual violence while accessing sanitation facilities. Due to lack of public toilet facilities women in coastal slums are forced to defecate at open places along the beach or they walk for long distances in search of hideouts, which is more prone and advantage to strangers/abusers, and it was the important reason for the high incidence of sexual violence there. Encountering outsiders like men elevates anxiety and may have repercussions for a woman's entire family. When compared to slums, women in resettlement colonies experience considerably less violence in accessing water and sanitation facilities as the households here have inbuilt toilets and water points near the households.

Thus, women living in Chennai city slums were subjected to live their life without dignity and not protected from human rights violation. Inadequate water and sanitation facilities found to be a potentially influencing factor for the same. Further, distance and time factor to access water and sanitation facilities found to be an influencing factor for sexual violence. Few studies have reported that gender-based violence can be avoided when women and girls are provided with services closer to home (Pommells et al. 2018). The study highlights that women in developmental infrastructure (resettlement colonies) face less violence compared to women in slums. The National and State Governments need to focus in developing affordable finance options for housing and infrastructure to the urban poor. Women should be empowered and strict legislations and regular monitoring by police specifically in risk areas where women face sexual violence should be made. Women should be included as a decision-making authority in policy level planning on water and sanitation issues which will enhance their leadership roles and empower them. Protecting and promoting their human rights will ensure their security, including freedom from violence and the threat of violence. Adequate and accessible water and sanitation facilities should be ensured, which will indirectly improve their access to education and employment and will improve the community as a whole.

\section{ACKNOWLEDGEMENTS}

The authors are thankful to Dr. G. Geetha for guidance and support. The authors are also thankful to Centre for Women's Development Studies and Indian Council for Social Science Research, New Delhi for financial support.

\section{REFERENCES}

Amnesty International. 2010a. Kenya: Insecurity and Indignity: Women's experiences in the slums of Nairobi, Kenya, pp. 59. Amnesty International, Mexico, USA.

Amnesty International. 2010b. Risking rape to reach a toilet: Women's experiences in the slums of Nairobi, Kenya, pp. 12. Amnesty International, Mexico, USA.

Bapat, M. and Agarwal, I. 2003. Our needs, our priorities; women and men from the slums in Mumbai and Pune talk about their needs for water and sanitation. Environment and Urbanization, 15(2): 71-86.

Chaplin, S.E. and Kalita, R. 2017. Infrastructure, Gender and Violence: Women and Slum sanitation inequalities in Delhi, pp. 52. Centre for Policy research, New Delhi.

Corburn, J. and Hildebrand, C. 2015. Slum Sanitation and the Social Determinants of Women's Health in Nairobi, Kenya. Journal of Environmental and Public Health, pp. 1-6. https://doi. org/10.1155/2015/209505

Gross, E., Gunther, I. and Schipper, Y. 2018. Women Walking and Waiting for Water: The Time Value of Public Water Supply. Economic Development and Cultural Change, 66(3): 489-517. 
Hulland, K.R.S., Chase, R.P., Caruso, B.A., Swain, R., Biswal, B., Sahoo, K.C., Panigrahi, P. and Dreibelbis, R. 2015. Sanitation, Stress, and Life Stage: A Systematic Data Collection Study among Women in Odisha, India. PLoS ONE, 10(11): 1-17.

Kayser, G.L., Rao, N., Jose, R. and Raj, A. 2019. Water, sanitation and hygiene: Measuring gender equality and empowerment. Bulletin of the World Health Organization, 97(6): 438-440.

Kulkarni, S., O'Reilly, K. and Bhat, S. 2017. No relief: Lived experiences of inadequate sanitation access of poor urban women in India. Gender \& Development, 25(2): 167-183.

Kwiringira, J., Atekyereza, P., Niwagaba, C. and Günther, I. 2014. Gender variations in access, choice to use and cleaning of shared latrines; experiences from Kampala Slums, Uganda. BMC Public Health, 14(1): 1180:1-11.

Lande, L.V.de. 2015. Eliminating discrimination and inequalities in access to water and sanitation. Policy and Analytical Briefs, pp. 29. UN Water, Geneva.

Lennon, S. 2011. Perceptions of risks related to sexual violence against women linked to water and sanitation in Delhi, India. Briefing Note, pp. 15. Sanitation and Hygiene Applied Research for Equity, London.

Mageswari, S. 2017. Water and Sanitation accessibility among urban slum women of Chennai city: An analytical study. Doctoral Thesis, University of Madras, Chennai, Tamil Nadu, India.

Massey, K. 2011. Insecurity and Shame: Exploration of the impact of the lack of sanitation on women in the slums of Kampala, Uganda. Briefing Note, pp. 11. Sanitation and Hygiene Applied Research for Equity, London.

Pommells, M., Wallace, C., Watt, S. and Mulawa, Z. 2018. Gender Violence as a Water, Sanitation, and Hygiene Risk: Uncovering Violence against women and Girls as it pertains to poor WaSH access. Violence Against Women, 24(15): 1851-1862.

Raj, U., Galhotra, A. and Roja, V. 2019. A study of utilization of sanitary facilities by adolescent girls in an urban slum of Central India. Journal of Family Medicine and Primary Care, 8(4): 1396-1400.
Sahoo, K.C., Hulland, K.R.S., Caruso, B.A., Swain, R., Freeman, M.C., Panigrahi, P. and Dreibelbis, R. 2015. Sanitation-related psychosocial stress: A grounded theory study of women across the life-course in Odisha, India. Social Science \& Medicine, 139: 80-89.

Sommer, M., Ferron, S., Cavill, S. and House, S. 2015. Violence, gender and WASH: Spurring action on a complex, underdocumented and sensitive topic. Environment and Urbanization, 27(1): 105-116.

Subbaraman, R., Nolan, L., Shitole, T., Sawant, K., Shitole, S., Sood, K., Nanarkar, M., Ghannam, J., Betancourt, T.S., Bloom, D.E. and Patil-Deshmukh, A. 2014. The psychological toll of slum living in Mumbai, India: A mixed methods study. Social Science \& Medicine, 119: 155-169.

Subbaraman, R., Shitole, S., Shitole, T., Sawant, K., O'Brien, J., Bloom, D.E. and Patil-Deshmukh, A. 2013. The social ecology of water in a Mumbai slum: Failures in water quality, quantity, and reliability. BMC Public Health, 13: 173:1-14.

Sverdlik, A. 2011. Ill-health and poverty: A literature review on health in informal settlements: Environment and Urbanization, 23(1): 123-155.

Tiwari, P. 2015. Toilet Torture in Mumbai's Slums: When will out political and administrative leaders end the daily assaults on women's safey and dignity, pp. 96. Observer Research Foundation, Mumbai.

Tutu, R.A. and Stoler, J. 2016. Urban but off the grid: The struggle for water in two urban slums in greater Accra, Ghana. African Geographical Review, 35(3): 212-226.

United Nations Human Settlements Programme. 2003. The challenge of slums: Global report on human settlements, 2003, pp. 345. Earthscan Publications, Nairobi, Kenya. 